Fernanda Beatriz Caricari de Morais

\title{
A REPRESENTAÇÃO DAS MULHERES NA POLÍTICA BRASILEIRA: UM ESTUDO SOB A PERSPECTIVA SISTÊMICO-FUNCIONAL ${ }^{1}$
}

\author{
(The representation of brazilian women in politics: \\ a study in the Systemic-functional perspective)
}

Fernanda Beatriz Caricari de Morais

(Pontifícia Universidade Católica-PUC/SP) ${ }^{2}$

\begin{abstract}
This study aims to analyze the representation of women politicians in articles. Linguistics Functional Grammar was used to analyze the ideational metafunction, so as to characterize the use of the language as representation. Results show that although Brazil had many social and politics changes, women and men had different representations. Many times, women are represented by their private lives and their female characteristics and not by their professional characteristics and competence. Men are represented by their competition and dishonesty.
\end{abstract}

Keywords: woman, politician, Linguistics Functional Grammar, written media.

\section{RESUMO}

O objetivo desta pesquisa é analisar a representação da mulher política em artigos de revistas de circulação nacional. Utilizou-se a Linguística Sistêmico-Funcional para a análise linguística, em especial, a metafunção

1. Este trabalho é um recorte de minha pesquisa de mestrado intitulada: As mulheres na política brasileira: um estudo sob a perspectiva sistêmico-funcional. Dissertação de mestrado em Linguística Aplicada e Estudos da Linguagem pela Pontifícia Universidade de São Paulo (PUC-SP) sob orientação da Profa. Dra. Leila Barbara.

2. Graduada em Letras - Inglês/Português pela Pontifícia Universidade Católica de Campinas, onde realizou projeto de inciação científica com foco na representação do feminino, sob supervisão da Profa. Dra. Astrid Sgarbieri. Possui Mestrado em Linguística Aplicada e Estudos da Linguagem pela Pontifícia Universidade de São Paulo (PUC-SP) sob orientação da Profa. Dra. Leila Barbara. Atualmente é doutoranda do mesmo programa sob a mesma orientação. 
ideacional que caracteriza o uso da linguagem como representação. Os resultados possibilitam dizer que apensar dos avanços políticos e sociais da sociedade brasileira, os homens e as mulheres políticas são representados de maneiras diferentes. Elas, muitas vezes, são representadas pelas suas vidas privadas e suas características femininas e não por suas características e competência profissionais. Eles são representados pelas suas disputas e desonestidades.

Palavras-chave: Mulher, política, Linguística Sistêmico-Funcional, mídia impressa.

\section{Introdução}

A pesquisa realizada fez parte do Projeto DIRECT (em direção à linguagem do trabalho), desenvolvido no Programa de Estudos de Pós Graduação em Linguística Aplicada e Estudos da Linguagem (LAEL) da PUC-SP e teve como objetivo geral descrever e analisar como profissionais da área política brasileira são representados, tendo como foco de análise da representação da mulher política em artigos de revistas de circulação nacional.

Como esta pesquisa está inserida na área da Linguística Aplicada, além de analisar a linguagem através de uma teoria linguística, buscase em uma outra área do conhecimento, a de Ciências Políticas, subsídios para o melhor entendimento do papel da mulher na política brasileira.

Pesquisas na área de Ciências Políticas, como o de Avelar (2001) e Grossi e Miguel (2001), contribuem para o melhor entendimento da importância e dos desafios da mulher na política. A questão central dessas pesquisas é a analise da participação efetiva das mulheres e considerações sobre as razões do lento processo de mudanças políticas do país e democratização da sociedade brasileira sem discriminação de gênero. Para realizar essas análises, apóia-se na Linguística SistêmicoFuncional de Halliday (1994, 2004) e seus seguidores como Eggins (1994) e Thompson (1996). A Linguística Sistêmico-Funcional (doravante LSF) é uma teoria de linguagem que está preocupada com o uso efetivo da linguagem em diferentes contextos. 
Fernanda Beatriz Caricari de Morais

As pesquisas linguísticas sobre mulheres, como a de Fabrício (2004) e a de Heberle (2005), e sobre mulheres políticas, como as de Sgarbieri $(2005,2006)$, servem como apoio nas discussões das representações feitas sobre a mulher política. Para a realização da presente pesquisa foram coletados 52 artigos que tratam da mulher política no período de 2002 a 2007 nos sites das revistas Veja, Época e Istoé. Essas publicações foram escolhidas por abordarem acontecimentos do cenário político brasileiro e circularem em todo território nacional. Após a coleta, os artigos foram tratados com o auxílio da ferramenta computacional WordSmith Tools (Scott, 1998), visando responder às seguintes perguntas sobre a representação das mulheres políticas:

1. Como a mulher política brasileira é representada pela mídia impressa? Essas representações são positivas, negativas ou neutras?

2. Quais escolhas linguísticas são responsáveis por esta representação?

3. Como se manifestam as diferenças e/ou semelhanças nas representações dos profissionais (homens e mulheres) na área política?

Para esta última pergunta cujo objetivo é a comparação, coletamos artigos sobre homens políticos nas mesmas publicações.

\section{As mulheres políticas brasileiras}

Apresenta-se, neste item, uma visão geral dos estudos sobre mulher política na área de Ciências Políticas e de Linguística Aplicada que serviram como base para a discussão dos dados. Os estudos sobre a participação das mulheres na vida política, no início do século $\mathrm{XX}$, colocaram em relevo aspectos relacionados com a evolução dessa participação sob a perspectiva de mudanças sociais, culturais e políticas da sociedade. Destacam-se as mudanças na família, novas formas de produção no mundo do trabalho com impacto nas relações sociais, as conquistas femininas ao longo do século XX e o amadurecimento 
de uma consciência feminista, mudanças que acabaram por abalar as estruturas seculares sobre as quais se assentava a dominação masculina em todas as esferas da vida pública. No caso do Brasil, as análises sobre mulheres na política levam em conta as razões do lento processo de mudanças políticas, principalmente no campo dos direitos de cidadania, conforme apontam os estudos de Avelar (2001).

Os direitos de cidadania são lentamente ampliados para os segmentos desprivilegiados. As mulheres são bons exemplos para se ter a idéia de quanto é longo o caminho da luta pela extensão real dos direitos de cidadania. A autora (op.cit.) enfatiza, ainda, que os movimentos urbanos dos anos 20 e 30 deixavam claro que as conquistas femininas não implicariam alterar a estrutura da sociedade e da família. Esses foram frutos da ação de mulheres de classe alta e reiteravam a política conservadora da época.

Somente em 24 de fevereiro de 1932 as mulheres conseguiram o direito ao voto por um decreto do presidente Getúlio Vargas. Os temas defendidos pelas feministas dos anos 30 eram: os interesses das mulheres trabalhadoras, a necessidade de instituir educação em colégios mistos, a mudança da legislação que reconhecia como incapaz a mulher casada, a política voltada às crianças abandonadas e a emancipação econômica das mulheres. O posicionamento ideológico das mulheres tornou-se mais claro na medida em que no país se construía um novo espaço, o espaço político da esquerda.

O feminismo, como uma ideologia política, é um elemento crucial na construção de identidades políticas femininas, porque é um conjunto estruturado de idéias que guia a ação política. A consciência de que as mulheres são discriminadas e não usufruem das mesmas condições de igualdade que os homens; a convicção de que isso é resultante da situação de desigualdade estrutural das mulheres na sociedade e do reconhecimento de que são necessárias soluções grupais, resultantes da ação coletiva, para a mudança em termos estruturais. Segundo Reis (2000), essa mudança é um processo cognitivo, intelectual, construído socialmente, e não apenas uma visão de mundo.

A luta feminista se insere na luta pela democratização de uma sociedade, e ela é idêntica àquela de qualquer outro grupo 
marginalizado da sociedade. Avelar (2001) toma as palavras de Reis (2000) para exemplificar esta luta pela democracia:

"Uma sociedade não será democrática na medida em que as oportunidades dos indivíduos estejam condicionadas por sua inserção nesta ou naquela categoria social: sejam quais forem os critérios com base nos quais tais categorias se constituam (raça, classe, etnia, religião, gênero...), a sociedade assim caracterizada será fatalmente hierárquica e autoritária,e as oportunidades diferenciais por categorias de expressarão, ao cabo, o desequilíbrio nas relações de poder entre elas e a subordinação de umas às outras". (AVELAR, 2001:26)

Apesar da luta feminista, no Brasil, a entrada das mulheres na política, segundo Grossi e Miguel (2001:12), é feita por dois grandes canais:

- Participação em movimentos sociais, como: grupos de bairro, sindicatos, etc.;

- Relações familiares, como o parentesco com um homem político, em geral, pai ou marido.

As autoras (2001) discutem que, para muitas mulheres, chegar à política pelo primeiro canal - o da participação em movimentos sociais, seria enobrecedor, mas chegar à política pelo segundo canal - o das relações de parentesco seria desabonador, pois entraria na política de forma facilitada por relações de clientelismo, presentes na cultura política brasileira. As mulheres que entram na carreira política pelo primeiro canal são valorizadas pelo seu esforço pessoal. Por outro lado, as que entram pelo segundo canal são acusadas de terem sido eleitas ilegitimamente, por terem se beneficiado tanto do prestígio, quanto das alianças feitas por um homem (pai ou do marido).

Representada como uma carreira com duplo sentido, a carreira política ora é representada como fruto de projeto coletivo ideológico, ora como fruto de um projeto totalmente individual. Por trás da crítica às mulheres políticas parece haver uma visão de que a política deveria ser somente uma vocação e não uma carreira que exigiria um longo processo de formação. 
As mulheres que seguiram tradições familiares no campo da política, a sua própria autoria e desejo, reconhecendo que muitas mulheres que contaram com o prestígio político dos seus maridos ou pais, tomaram rumos independentes e, muitas vezes, até superaram o prestígio dos seus familiares. Pode-se chamar a representação da mulher política de sub-representação política, por ser a mesma das de outros grupos em condição de desigualdade nas condições de vida e na estrutura das oportunidades. Como outros grupos da sociedade menos privilegiados, as mulheres encontram-se fora dos processos de decisão política. Há muito o que avançar rumo à igualdade entre os sexos, avanços que são lentos quando não há mulheres na política que defendam temas que levariam à igualdade.

O número de mulheres nas cúpulas partidárias brasileiras é ainda muito pequeno. Se for analisada a presença feminina conforme a tendência ideológica dos partidos, vemos que a maior presença das mulheres encontra-se nos partidos de direita. Nos partidos constituídos pelas forças políticas de esquerda, ainda é pequena a participação da mulher, como mostram os quadros abaixo sobre o número de mulheres senadoras e deputadas:

\begin{tabular}{|l|l|l|l|l|}
\hline \multicolumn{1}{|c|}{ Partido } & $\begin{array}{c}\text { Deputadas } \\
\text { Federais }\end{array}$ & Senadoras & Total & Total (\%) \\
\hline PC DO B & 5 & 0 & 5 & 8,93 \\
\hline PDT & 1 & 0 & 1 & 1,79 \\
\hline PFL & 5 & 4 & 9 & 16,07 \\
\hline PMDB & 9 & 0 & 9 & 16,07 \\
\hline PP & 3 & 0 & 3 & 5,36 \\
\hline PPS & 1 & 0 & 1 & 1,79 \\
\hline PR & 4 & 0 & 4 & 7,14 \\
\hline PSB & 6 & 1 & 7 & 12,50 \\
\hline PSDB & 3 & 2 & 5 & 8,93 \\
\hline PT & 7 & 3 & 10 & 17,86 \\
\hline PTC & 1 & 0 & 1 & 1,79 \\
\hline Sem partido & 1 & 0 & 1 & 1,79 \\
\hline Total & 46 & 10 & 56 & 100,00 \\
\hline
\end{tabular}

Tabela 1: Senadoras e deputadas dos maiores partidos políticos brasileiros

(Fonte: site da organização Cfêmea, 2007) 
Conforme tabela acima, a participação das mulheres no Senado e na Câmara ainda é muito baixa. Se esses dados forem comparados com os referentes aos homens, tem-se uma diferença alarmante, como na tabela abaixo:

\begin{tabular}{|l|l|l|l|l|l|}
\hline Mandato & Mulheres & Mulheres (\%) & Homens & Homens (\%) & Total \\
\hline $\begin{array}{l}\text { Deputados(as) } \\
\text { Federais }\end{array}$ & 46 & 8,98 & 466 & 91,02 & 512 \\
\hline Senadores(as) & 10 & 12,35 & 71 & 87,65 & 81 \\
\hline Total & 56 & 9,44 & 537 & 90,56 & 593 \\
\hline
\end{tabular}

Tabela 2: Diferentes representações por sexo. (Fonte: site da organização Cfêmea, 2007).

Segundo a tabela acima, as mulheres representam menos de 10\% dos senadores e deputados brasileiros, este número é muito pequeno se pensar-se na política de cotas adotada pelo Governo em 1996 para obrigar os partidos a investirem nas candidaturas femininas. A União Inter-Parlamentar referencia o Brasil se encontra na $104^{\mathrm{a}}$ posição no ranking de presença de mulheres no parlamento no mundo. Entre os países do continente latino-americano, fica atrás, apenas, da Guatemala e do Haiti.

A sub-representação é um problema a ser resolvido, pois trata de uma questão de democratização da representação e de justiça para com um desequilíbrio que foi decorrente de vetos políticos históricos e desvantagens socioeconômicas, derivadas de preconceitos e valores de gênero. Há poucos estudos em Linguística e Linguística Aplicada que tratam da representação da mulher política brasileira. Sgarbieri (2003, 2005) analisou a mulher política em artigos de revistas de informação, como esta pesquisa também analisa,Veja, Época e Istoé e mostrou que as mulheres são muitas vezes representadas pelos seus atributos femininos e seus parentescos políticos.

Há diversos trabalhos sobre a representação feminina, entre les: Widholzer (2005), Gastalo (2005), Bisol (2005) e Sabat (2005), que estudam as representações das mulheres no discurso publicitário. 
Caldas-Couthard $(1997,2005)$ analisa no primeiro estudo como a mulher é descrita em notícias de jornais ingleses, mostrando em suas análises que as mulheres são sub-representadas, suas vozes são menos ouvidas e suas presenças menos significantes. No segundo, a autora analisa como as mulheres são representadas em narrativas na revista feminina de forma submissa em Marie Claire. Heberle (2005) analisa as representações de identidade e gênero em ambientes multimidiáticos na internet e Fabrício (2004) problematiza o papel das histórias narradas pela imprensa escrita na construção da idéia de identidades generificadas e questiona mitos da mulher frágil, incapaz e descontrolada emocionalmente.

\section{A Linguística Sistêmico-Funcional}

Esta pesquisa tem como fundamentação teórica a Linguística Sistêmico-Funcional de Halliday (1985, 1994, 2004) e seus seguidores Eggins (1994), Thompson (1996), entre outros. A LSF tem como foco a linguagem em uso, por isso sua preocupação é explorar como a língua é estruturada para o uso em diferentes contextos. Eggins (1994:40) baseada em Halliday (1985) define que uma das premissas básicas da abordagem sistêmico-funcional é que o uso da língua é motivado pelas relações sociais e que as escolhas léxico-gramaticais realizadas pelos falantes/escritores não são aleatórias e estão condicionadas pelo contexto.

Halliday (1994:14) explica que na LSF a língua é interpretada como um sistema de significados que são realizados através das formas linguísticas. A língua é vista como uma rede de escolhas, em que as formas linguísticas são analisadas levando-se em conta outras possibilidades oferecidas pela língua. A análise do texto, em termos gramaticais, é considerada o primeiro passo para a análise. A realização de um texto acontece através das relações semânticas e gramaticais. A gramática é requerida por fornecer uma compreensão clara do sentido e da efetividade de um texto, por isso precisa ter esta orientação semântica e funcional. A interpretação de um texto, 
Fernanda Beatriz Caricari de Morais

seja este oral ou escrito, deve levar em conta o contexto de sua produção.

Na LSF, a funcionalidade, segundo Halliday (1994:20) significa ser baseada no significado e, o fato de ser gramática é entendido como a interpretação das formas linguísticas. Por isso, a gramática separa as possíveis variáveis e aponta suas possíveis funções para podemos dar a nossa interpretação de um texto tanto pela sua descrição semântica como pelas características linguísticas. A linguagem é vista como prática social, cujo uso é motivado por uma finalidade, por isso ela é um recurso usado pelos seres humanos para criar significados. Nessa perspectiva, como aponta Halliday (1985:4), a LSF estuda as maneiras pelas quais as pessoas utilizam a linguagem para atingir determinados objetivos em situações específicas dentro de uma sociedade.

Para saber o que significa uma escolha, precisa-se ver o contexto: o que isto significa na sociedade? quais são os fatores contextuais que fazem uma escolha ser mais apropriada que outra? As escolhas linguísticas precisam ser identificadas, ou seja, as possibilidades lexicais e estruturais que a língua oferece para o uso precisam ser exploradas, assim como, os significados que cada escolha expressa (Thompson, 1996:8).

Ao fazer uma determinada escolha, o falante/escritor realiza três tipos de significados simultaneamente:

- Significados relacionados às representações de poder e solidariedade, o que engloba as atitudes em relação ao outro e os papéis sociais desempenhados;

- Significados relativos à representação da experiência através da língua, sobre o que se fala e sobre o que (ou quem) age sobre o que (ou quem);

- Significados relativos à organização do conteúdo da mensagem, em relação com o que se diz e ao que foi dito.

Esses três tipos de significado estão relacionados com cada metafunção da linguagem: interpessoal, ideacional e textual. Para a análise da representação da mulher política, concentra-se na metafunção ideacional que reflete a representação sobre padrões de experiência, 
realidade e a experiência do que acontece dentro das pessoas, por isso, reflete a representação sobre o mundo. Nessa metafunção, a oração tem um papel central, pois é nela que se incorpora um princípio geral de modelagem da experiência, que é o princípio de que a realidade é construída através dos processos, dos participantes e das circunstâncias.

O primeiro é a ação ou estado propriamente ditos e representase por um grupo verbal. Os participantes são representados por grupos nominais ou pronominais. São aqueles que realizam as ações ou são afetados por elas. As circunstâncias representam-se por grupos adverbiais e sua função é de acrescentar informação (ões) às ações representadas pelos processos. Halliday (1994) explica que há três tipos de processo principais - o material, o mental e o relacional. Os demais, chamados intermediários, são: o comportamental, o verbal e o existencial. Para este artigo, optou-se por focar os processos relacionais por ser eles o responsáveis pela atribuição de características, identificações e avaliações no texto. O processo relacional são os da ordem do ser.

\section{Procedimento de coleta e tratamento dos dados}

Para responder as duas primeiras perguntas de pesquisa, este trabalho utilizou um corpus formado por 52 artigos cujo tópico principal ou titulo, se refere à mulher política, corpus que denominouse mulher política (MP). Para a questão de número três, foi formado um outro corpus com 52 artigos que fazem referência a políticos homens (HP). Para compor este último corpus, foram selecionados arquivos que tratavam de políticos em geral.

Inicialmente, analisou-se como as mulheres são representadas. Com base nessa análise e levando em conta a baixa participação política das mulheres, decidiu-se coletar artigos que fazem referência ao homem político com o propósito de analisar as possíveis diferenças e/ou semelhanças, dependendo do gênero do profissional enfocado.

Os artigos selecionados foram gravados em arquivos individuais no formato txt e foram submetidos a um tratamento de Linguística de 
Corpus através das ferramentas lista de palavras e concordanciador do programa computacional WordSmith Tools 4.0 (Scott, 1998), que serão descritas a seguir. O quadro acima foi retirado dos números estatísticos da ferramenta wordlist do programa WordSmith Tools 4.0 (Scott, 1998), apresentado no item seguinte.

\begin{tabular}{|l|c|c|}
\hline \multicolumn{1}{|c|}{ Estatísticas } & Corpus de MP & Corpus de HP \\
\hline Total de palavras & 194.839 & 190.234 \\
\hline Palavras diferentes & 6.489 & 5.939 \\
\hline Tokens (running words) & 32.750 & 31.829 \\
\hline Períodos & 1.568 & 1.600 \\
\hline No. de palavras do menor artigo & 81 & 1.200 \\
\hline No. de palavras do maior artigo & 1713 & 11.412 \\
\hline
\end{tabular}

Tabela 3: Resultado estatístico dos corpora.

Os corpora foram submetidos a um tratamento computacional possibilitado pela Linguística de Corpus (LC) que se faz presente metodologicamente, nesta pesquisa, através de ferramentas do programa WordSmith Tools 4.0 (Scott, 1998).

Atualmente a LC, segundo Berber-Sardinha (2004), fornece subsídios teóricos e metodológicos para muitas áreas da Linguística Aplicada (Ensino de Línguas, Tradução, Análise do Discurso, Lexicografia, etc), porque trabalha dentro de um quadro conceitual formado por uma abordagem empirista e uma visão de linguagem enquanto sistema probabilístico. O programa foi escolhido como instrumento de análise de dados, pois possibilita o trabalho com uma grande quantidade de textos, além de dispor de uma série de recursos que são extremamente úteis e poderosos na análise de vários aspectos da linguagem, como: a composição lexical, a temática de textos selecionados e a organização retórica e composicional de gêneros discursivos.

Utilizamos duas das suas principais ferramentas para a análise: a lista de palavras (wordlist) e o concordanciador (concordancer) ${ }^{3}$. A

3. Como o programa está em Inglês, colocou-se em parênteses o nome das ferramentas no original. 
primeira foi utilizada para organizar os corpora em listas das palavras. Elas podem ser ordenadas alfabeticamente ou pela frequência com que aparecem, começando pela palavra de maior frequência. Nesta mesma ferramenta, foram obtidos dados estatísticos dos textos: número de palavras (tokens) e de palavras diferentes (types), número de orações (sentence), etc. Ela nos ajudou tanto na organização dos dados estatísticos como na análise das palavras mais frequentes utilizadas para nomear os profissionais políticos.

Através das listas de concordâncias foi possível estudar o contexto de ocorrência das palavras de busca simultaneamente em todo o corpus. Esta análise, com base na Linguística Sistêmico-Funcional, que é uma teoria de linguagem e um método de análise de textos em seus contextos de uso permite entender como os indivíduos usam a linguagem e como a linguagem é estruturada em seus diferentes usos.

O suporte da LSF possibilita a analise de como os profissionais da área política são representados nos artigos e as diferenças e as semelhanças na representação do homem político e da mulher política. Halliday (1994:15) discute que qualquer análise de discurso é sempre feita em dois níveis; o primeiro é a compreensão do texto: a análise linguística permite que se mostre como e por que o texto significa o que significa; o outro nível é uma contribuição à avaliação do texto: a análise linguística permite que se diga o motivo pelo qual o texto é ou não um texto eficaz para os seus propósitos, e requer não somente uma compreensão do texto, mas também de seu contexto (contexto de cultura e contexto de situação) e do relacionamento sistemático entre o contexto e o texto.

\section{Análise e discussão dos resultados}

As análises preliminares permitiram dividir as ocorrências em categorias maiores, baseadas tanto na semântica, ou seja, sobre o que elas tratam, como nos elementos da transitividade. Além dos processos, há outros elementos (participantes e circunstâncias) que podem conduzir às categorias maiores, detalhadas a seguir: 


\begin{tabular}{|l|l|}
\hline \multicolumn{1}{|c|}{ Categorias } & \multicolumn{1}{c|}{ Assuntos abordados } \\
\hline a. estratégias políticas & $\begin{array}{l}\text { Diferentes estratégias utilizadas pelos políticos } \\
\text { em situações de disputas. }\end{array}$ \\
\hline b. reconhecimento político & $\begin{array}{l}\text { Formas como os políticos são reconhecidos } \\
\text { publicamente. }\end{array}$ \\
\hline c. honestidade & $\begin{array}{l}\text { Desonestidades cometidas por políticos } \\
\text { homens. }\end{array}$ \\
\hline d. aparência & $\begin{array}{l}\text { Como os políticos são representados pelas } \\
\text { aparências. }\end{array}$ \\
\hline e. relacionamentos familiares & $\begin{array}{l}\text { A importância dos relacionamentos familiares } \\
\text { na vida política. }\end{array}$ \\
\hline
\end{tabular}

Quadro 2: Categorias de análise

Através das categorias apresentadas, organizou-se a análise com foco na representação da mulher política, quais são as escolhas lexicais que expressam e realizam esta representação e quais são as diferenças e/ou semelhanças com os homens políticos.

As categorias de análise mostram, a seguir, que os profissionais políticos são constantemente identificados e avaliados pela mídia jornalística por meio de processos relacionais, utilizados para estabelecer relações entre duas entidades, identificando ou atribuindo características a algo ou a alguém.

\section{a) estratégias políticas}

Os exemplos abaixo representam dois candidatos, Marta Suplicy e Garibaldi Alves Filho (PMDB-RN) em véspera de eleições:

1. Marta salientou que, por enquanto, é a única candidata indicada pelo partido. (Época 16/12/2003).

2. Alves é o único peemedebista que já se lançou candidato à sucessão do alagoano Renan Calheiros. (Época 04/12/2007).

Estas orações intensivo-identificadoras representam os candidatos Marta e Alves com destaque por serem identificados como únicos, como mostram os identificadores a única candidata... e $o$ 
único peemedebista.... Marta, em sua fala, auto identifica-se como a única candidata mulher na disputa pelo Governo do Estado de São Paulo indicada pelo seu partido, o PT. Da mesma forma como Alves que é identificado como o único candidato de seu partido (PMDB) à sucessão de Renan Calheiros (PMDB-AL).

Assim como Marta se auto-identificou como a única candidata mulher do partido, foram encontrados, nos artigos de HP, outras identificações feitas pelos jornalistas sobre os candidatos Eduardo Suplicy e Geraldo Alckmin:

3. Ele éo homem a ser batido nas eleições para o Senado em São Paulo. (Istoé 15/03/2006).

4. Por enquanto, é ele o nome com mais chances de disputar o segundo turno com Lula. (Istoé 18/06/2006).

Em ambos tem-se orações intensivos-identificadoras. $\mathrm{O}$ identificador em 3 enfatiza a disputa política e identifica Suplicy como um candidato a ser derrotado pelos adversários nas eleições. Analisou-se esse identificador, também, como uma alusão à invencibilidade de Suplicy, pois ele possui um eleitorado cativo no Estado de São Paulo.

De forma diferente, em 4, temos a identificação do candidato Alckmin (identificado) como o único com chances de disputar o segundo turno nas eleições presidenciais. Notou-se que o identificador, aqui, coloca Lula como o candidato mais forte da disputa presidencial.

Assim como os candidatos acima foram destacados, os exemplos abaixo destacam a Senadora Heloísa Helena tanto por ser a primeira mulher a concorrer à Presidência, como por mostrar coragem e enfrentar um político poderoso:

5. Candidata arretada. Expulsa do PT em 2003, Heloísa Helena é a primeira mulher de expressão a concorrer à Presidência no Brasil. (Veja 07/06/2006).

6. Foi a primeira pessoa a enfrentar o cacique baiano Antonio Carlos Magalhães no Congresso Nacional - uma briga que até hoje lhe rende acusações pessoais e inimizades ferozes. (Época 10/02/2003). 
Tem-se processos relacionais do tipo intensivo-identificador nos exemplos acima. O primeiro identificador (5) mostra a baixa participação das mulheres no cenário político, conforme aponta Avelar (2001) em suas pesquisas. A participação feminina ainda é muito pequena no país e, embora com poucas mulheres envolvidas na política, houve um progresso, em especial, por ter a candidatura da primeira mulher no Brasil, no ano de 2006.

Ainda em 5, no início da oração, temos Candidata arretada, chamada na LSF como oração menor. Para Halliday (2004:153) as funções das orações menores são: exclamações, chamadas, cumprimentos e alarmes. No caso de 5, a oração menor tem função exclamativa e interpretou-se o seu uso como um grito súbito de admiração, geralmente utilizado na fala. Na escrita é acompanhado do sinal gráfico de exclamação, ausente neste exemplo. O atributo arretada é muito utilizado no nordeste do país e entende-se seu significado como sinônimo de "bacana" e "excelente" e é utilizado, aqui, para apreciar a candidata.

$\mathrm{Na}$ segunda oração, neste mesmo exemplo, há uma nominalização em expulsa do $P T$ a partir de uma oração passiva que remete a um fato marcante tanto na política brasileira, na história do partido, como na vida política da Senadora. Em seguida, o identificador da oração relacional intensivo-identificadora atribui à Heloísa Helena a identificação de ser a primeira mulher de expressão a concorrer à presidência, representando-a como uma figura política importante. A menção da expulsão da Senadora foi interpretado como um recurso para mostrar sua força, sua luta pelos ideais originais do PT e não por interesses próprios.

Em 6, o identificador enfatiza a coragem da Senadora Heloísa Helena (identificado) ao enfrentar um político poderoso em público, como temos na circunstância no Congresso Nacional. Nota-se que a Senadora não foi a primeira mulher, mas sim, a primeira pessoa a enfrentá-lo, o que mostra um avanço na sociedade, pois as mulheres passam a ser vistas não mais como seres frágeis e desprovidos de atitudes, mas como profissionais que podem fazer diferença na política. A consequência desta briga, enfocada no final do exemplo, salienta ainda mais a coragem da Senadora. 
Encontrou-se, em um artigo sobre HP, um exemplo do Ministro da Saúde, José Gomes Temporão que se assemelha e ao mesmo tempo difere da referência acima sobre Heloísa Helena:

7. Seu jeito direto de quem está sempre disposto a comprar brigas é mais associado ao estereótipo masculino. Em apenas dois meses no cargo, Temporão já arrumou confusão para um mandato inteiro. Por defender o debate sobre a legalização do aborto, atraiu a ira da Igreja Católica. (Época 05/11/2007).

Há uma aparente semelhança entre as representações da senadora Heloísa Helena e do ministro Temporão, pois ambos são representados como profissionais que compram brigas. Enquanto no exemplo anterior, Heloísa é representada por brigar com um político poderoso, Antônio Carlos Magalhães, a circunstância do processo material arrumou, em 16, enfatiza que em pouco tempo de mandato Temporão causou muita polêmica, como observou-se no processo mental atraiu e no fenômeno desse processo a ira da Igreja Católica. Destaca-se a comparação da postura briguenta do Ministro com o estereótipo masculino, como no atributo mais associado ao estereótipo masculino. Interpretou-se isto como uma afirmação machista do jornalista, pois as mulheres também podem adotar essa postura na política, como Heloísa Helena nos exemplos analisados.

\section{b) reconhecimento político}

Nos exemplos abaixo, os autores descrevem as qualidades de algumas mulheres políticas:

8. A ex-prefeita Marta Suplicy, de São Paulo, é um dos fenômenos politicos mais interessantes do Brasil. (Veja 23/03/2005).

9. O PSOL não terá muito brilho político nem hoje nem no futuro... Isso não impedirá a senadora Heloísa Helena de se firmar como uma respeitável figura política, coisa que ela já é. (Veja 16/06/2004).

As orações intensivas-identificadoras identificam as participantes (Marta Suplicy e Heloísa Helena) como profissionais de destaque 
Fernanda Beatriz Caricari de Morais

na política brasileira, através dos identificadores: um dos fenômenos mais interessantes... e uma respeitável figura política. Analisouse, em 9, o processo firmar como material, pois o interpretamos como sinônimo de estabilizar. Firmar também tem como meta uma respeitável figura política, representando Heloísa Helena como uma profissional experiente, devido a sua vivência na carreira política. De acordo com o significado de fenômeno, parte do identificador, Marta é representada como uma política que possui qualidades extraordinárias e surpreendentes.

Nos exemplos seguintes temos mais identificadores sobre o desempenho político da senadora Patrícia Saboya e do Ministro da Saúde Temporão:

10. Aos 41 anos, a senadora Patrícia Saboya Gomes (PPS-CE) é uma estrela emergente no Congresso Nacional. Preside uma CPI mista para investigar a exploração sexual de crianças e adolescentes, é vice-líder do governo, coordena a Frente Parlamentar da Criança e do Adolescente e integra a Comissão de Assuntos Econômicos, a mais poderosa do Senado. (Época 17/07/2003).

11. Temporão é um dos ministros mais ativos do governo Lula. Trabalha em média 12 horas por dia e é reconhecido como um talento na área de saúde pública. (Época 05/11/2007).

Em 10, Patrícia Gomes é identificada como uma profissional que ganhou destaque na política. Nota-se, no artigo, a remição ao início da sua carreira - acompanhando o seu ex-marido, Ciro Gomes. Depois da separação, Patrícia ganhou um grande destaque devido ao seu trabalho, como mostram os processos materiais: preside, coordena e integra e suas respectivas metas; e o relacional é e seu atributo vicelíder do governo.

Os temas trabalhados por Patrícia ganharam destaque; ela integra tanto comissões ligadas ao social (crianças e adolescentes), como a econômica, enfatizada, no final da oração, como a comissão mais poderosa do Senado. Avelar (2001) aponta, em seus estudos, que a maioria das mulheres trabalha com temas relacionados ao social e os temas econômicos são, em geral, trabalhados por políticos 
homens. Pode-se, portanto, notar um progresso na política brasileira, já que Patrícia trabalha com temas ligados tanto ao social como ao econômico.

No último exemplo, por meio da meta e do fenômeno dos processos trabalha (material) e reconhecido (processo mental) está o então ministro Temporão, responsável pela área da saúde, representado como um político trabalhador e com bons desempenhos na política.

\section{c) honestidade}

Chamou-nos a atenção, nos artigos sobre HP, as ocorrências envolvendo diferentes políticos em situações desonestas, o que não aconteceu ao analisar os artigos que fazem referência à MP. Buscou-se ocorrências, nos dados de MP, que envolviam casos de desonestidade, mas apenas foram encontradas avaliações negativas sobre seus desempenhos profissionais, por isso pode-se inferir que as mulheres não estão envolvidas nessas situações, por parecerem ser mais honestas que os homens.

Aqui os processos relacionais possuem função de auxiliar nas construções passivas com o processo cassado tratam de diferentes políticos em situações políticas delicadas. Alguns foram cassados por corrupção e outros por participarem de crimes, como mostram os exemplos abaixo:

12. Foi cassado na noite de quinta-feira, pela Câmara Legislativa de Brasília, o mandato do deputado distrital Carlos Xavier (PMDB), acusado de ordenar o assassinato de um adolescente identificado como suposto amante de sua ex-esposa. (Veja 06/08/2004).

13. O mandato de deputado de Hildebrando foi cassado em 1999, por quebra de decoro parlamentar, após investigações sobre o crime organizado no Acre. Ele já foi condenado por tráfico de drogas, formação de quadrilha e crime eleitoral. Até a decisão de hoje, as penas de Hildebrando chegavam a quase 70 anos. (Veja 29/11/2006).

14. O deputado Roberto Jefferson (PTB-RJ) foi cassado na noite desta quarta-feira em votação secreta na Câmara pela maioria dos votos dos parlamentares, que preencheram cédulas impressas. (Veja 14/09/2005). 15. Entre os novos deputados, circula discreto pelo Congresso o gaúcho 
Fernanda Beatriz Caricari de Morais

Ibsen Pinheiro, do PMDB. Ele retorna depois de ter sido cassado como um dos integrantes da máfia do Orçamento. (Istoé 21/02/2007).

Os dois primeiros exemplos tratam da cassação de dois deputados em situações relacionadas com o crime, apresentam processos verbais na voz passiva: acusado e condenado. Nota-se que na passiva o participante que ocupa a posição de sujeito é o político; a omissão do agente é um recurso comum do texto que não explicitar o agente responsável pela ação. Em 13, além de ter participado do crime organizado, o texto apresenta um histórico sobre outras desonestidades cometidas pelo Deputado, explicitadas na circunstância do processo verbal condenado.

Em 14, o processo material mostra o deputado punido com cassação por ter participado de esquemas de corrupção, o mensalão. Em 15, o deputado volta à vida pública tendo sido cassado (processo material retorna) e sua circunstância que também contém o processo cassado na passiva.

\section{d) aparência}

Nesta categoria, apresentam-se como os profissionais da política são representados pelas suas aparências. A maioria dos exemplos remete às mulheres políticas, que são frequentemente representadas pelas características ligadas à feminilidade. Nos artigos que tratam de políticos homens, há poucas ocorrências desse tipo de representações. A ocorrência encontrada remete a um único político - o ex-presidente Fernando Collor de Melo.

Uma das características femininas mais identificadas nos dados é a beleza física, que muitas vezes, no discurso jornalístico, é enfatizada em detrimento de sua atuação profissional, como em 16 e 17 :

16. Salto alto, leveza, fina estampa e atuação combativa. Com essas armas, Rita Camata (PMDB-ES), a escolhida para ser a vice do candidato tucano José Serra, tem a missão de barrar a curva ascendente de Luiz Inácio Lula da Silva (PT). (Época 27/05/2002). 
17. Além de ser mulher e bonita - fatores que podem ser decisivos numa etapa em que 23\% do eleitorado feminino ainda não tem candidato-, Rita é uma política de primeira linha. Chegou a Brasília como a Musa da Constituinte, em 1987, mas 15 anos depois figura entre os mais respeitados da casa. (Época 27/05/2002).

Os exemplos acima foram retirados de um mesmo artigo que apresenta Rita Camata como candidata à vice-presidente nas eleições presidenciais. No início do primeiro exemplo, salienta-se a descrição de Rita por meio das particularidades femininas e somente a última remete à característica profissional. Em 16, as primeiras características de Rita, encontradas no atributo mulher e bonita, também enfatizam o seu lado feminino. Nota-se que a atuação profissional aparece apenas posteriormente, como mostra o identificador seguinte uma política de primeira linha. A última oração, deste exemplo, ilustra que inicialmente Rita era considerada uma musa e somente 15 anos depois foi considerada uma política respeitada, o que permite dizer que a mulher política além de ser representada pelo seu trabalho e pelas suas características profissionais é representada como mulher (pela sua beleza e pelas suas características femininas).

\section{e) relacionamentos familiares}

Nesta categoria, apresenta-se como os políticos são representados através de suas relações familiares. Conforme abordado anteriormente, uma das formas de entrada da mulher no cenário político brasileiro é através das relações familiares, como o parentesco com um homem político, em geral, marido ou pai, como podemos ver nos exemplos 18 e 19 :

18. ... ele [Gerson Camata] é uma velha figura da política capixaba. (Época 27/05/2002).

19. Já o senador Eduardo Suplicy seria, para Marta, antes uma solução que um problema. Tradicional campeão de votos, o petista é um cabo eleitoral e tanto. (Veja 28/07/2004). 
Fernanda Beatriz Caricari de Morais

Em 18 e 19 há orações relacionais do tipo intensivoidentificadoras. Seus identificadores mostram a experiência política do marido de Rita Camata e do ex-marido de Marta Suplicy. Podese notar que ambos os políticos são os identificados das orações. A circunstância em 19, tradicional campeão de votos, é utilizada para avaliar Suplicy como um político querido e popular entre os eleitores e que poderia contribuir para uma boa imagem na campanha da exmulher Marta Suplicy. Nos artigos sobre MP, foram encontradas ocorrências em que as carreiras das mulheres políticas são influenciadas pelas de seus maridos políticos, mas o mesmo não ocorre nos artigos de HP. Não foi encontrada nenhuma ocorrência que os representasse através de suas esposas políticas. Acredita-se que o motivo se deve à baixa participação das mulheres na política.

\section{Considerações finais}

De modo geral, foram descritas as ocorrências frequentes a respeito do reconhecimento do profissionalismo das mulheres e da conquista de seu espaço na política. Algumas políticas são bastante populares e queridas pela população. Os homens políticos, ao contrário, possuem poucas ocorrências ligadas ao reconhecimento e à popularidade. Apenas dois políticos, Eduardo Suplicy e José Temporão, são representados por sua honestidade, competência e popularidade.

Acredita-se que esses aspectos apontam para mudanças na representação das mulheres. Levando em conta que a política, em nosso país, é uma área em que a grande maioria é homem, as mulheres estão mostrando-se competentes e conquistando mais espaço.

Deve-se lembrar que a mudança na representação das mulheres políticas é um processo longo e que envolve aspectos sociais e culturais de nossa sociedade. Espera-se que com o aumento da participação feminina contribua para o desenvolvimento político e social do nosso país.

Como esta é uma pesquisa desenvolvida na área de Linguística Aplicada, estudou-se a linguagem das revistas dentro de um contexto 
social e espera-se, com este trabalho, ter contribuído para o melhor entendimento das representações das mulheres políticas em nossa sociedade.

Esta pesquisa está delimitada em um período de 2002 a 2007, julga-se interessante um trabalho sobre a atual representação das mulheres políticas já que houve mudanças na conjuntura política e, hoje, tem-se uma mulher no cargo máximo - a presidente Dilma Rousseff. Outro aspecto importante é analisar se os homens políticos são representados de forma diferente ou não pela mídia brasileira.

Recebido em: julho de 2012 Aprovado em: setembro de 2012 caricari@terra.com.br

\section{Referências bibliográficas}

AVELAR, L. Mulheres na elite política brasileira. São Paulo: Editora da UNESP, 2001.

BERBER SARDINHA, T. Linguística de Corpus. Barueri-SP: Manole, 2004.

BISOL, A. L. W. Representações de gênero na publicidade turística. In: FUNCK, S. B. \& WIDHOLZER, N. (org). Gênero em discursos na mídia. Florianópolis: EDUNISC, 2005.

CALDAS-COULTHARD, C. R. News as social practice. Florianópolis: UFSC, 1997.

CALDAS-COULTHARD, C. R. O picante sabor do proibido: narratives pessoais e transgressão. In: FUNCK, S. B. \& WIDHOLZER, N. (org). Gênero em discursos na mídia. Florianópolis: EDUNISC, 2005.

CFEMEA (Centro Feminista de Estudos e Assessoria). 2006. Dados estatísticos: poder e política. Disponível em www.cfemea.org (Capturado em 13/12/2007).

EGGINS, S. An introduction to Systemic Functional Linguistics. London: Pinter Publishers, 1994. 
Fernanda Beatriz Caricari de Morais

FABRÍCIO, Branca F. Mulheres emocionalmente descontroladas: identidades generificadas na mídia contemporânea. DELTA. Documentação de Estudos em Linguística Teórica e Aplicada.v. 20, n.2, p.235-263, 2004.

GASTALO, E. A representação do espaço doméstico e papéis de gênero na publicidade. In: FUNCK, S. B. \& WIDHOLZER, N. (org) Gênero em discursos na mídia. Florianópolis: EDUNISC, 2005.

GROSSI, Mírian P. \& MIGUEL, Sônia M. Transformando a diferença: mulheres na política. Revistas de estudos feministas. V. 9, n. 1. Florianópolis: Editora UFSC, 2001.

HALLIDAY, M. A. K. Introduction to Functional Grammar. First edition. London: Edward Arnold, 1985.

HALLIDAY, M. A. K. An introduction to Functional Grammar. London: Edward Arnold., 1994.

HALLIDAY, M. A. K. An introduction to Functional Grammar. London: Edward Arnold, 2004.

HEBERLE, V. M. Gêneros e identidades no ciberespaço. In: FUNCK, S. B. \& WIDHOLZER, N. (org) Gênero em discursos na mídia. Florianópolis: EDUNISC, 2005.

REIS, F. W.. Solidariedade, interesses e desenvolvimento político. In: REIS, F. W. 2000. Mercado e utopia. São Paulo: Edusp, 2000

SABAT, R. Imagens de gêneros e produção de cultura. In: FUNCK, S. B. \& WIDHOLZER, N. (org) 2005. Gênero em discursos na mídia. Florianópolis: EDUNISC, 2005.

SCOTT, M. R. Wordsmith Tools 4. Software for text analysis. Oxford University Press, 1998.

SGARBIERI, A. K.E.L.N.. Representações do gênero feminino na mídia impressa. Cadernos de Estudos Linguísticos. V. 1, p. 366-371, 2006

SGARBIERI, A.K.E.L.N. Mídia, ideologia e preconceito: Análise do discurso crítica. In: Funck, Nara W. \& Bornéo, Susana (Org.). Gênero em discurso na mídia. Florianópolis: Editora Mulheres e EDUNISC, 2005.

THOMPSON, G. Introducing functional grammar. London: Arnold, 1996.

WIDHOLZER, N. A publicidade como pedagogia cultural e tecnologia de gênero: abordagem linguístico-discursiva. In: FUNCK, S. B. \& WIDHOLZER, N. (org) 2005. Gênero em discursos na mídia. Florianópolis: EDUNISC, 2005. 